\title{
Decreased metastatic phenotype in cells resistant to Aminolevulinic acid-Photodynamic therapy
}

\author{
Adriana Casas ${ }^{\mathrm{a}}$, Gabriela Di Venosa ${ }^{\mathrm{a}}$, Silvia Vanzulli ${ }^{\mathrm{b}}$, Christian Perotti $^{\mathrm{a}}$, Leandro \\ Mamome $^{\mathrm{a}}$, Lorena Rodriguez ${ }^{\mathrm{a}}$, Marina Simian ${ }^{\mathrm{C}}$, Angeles Juarranz ${ }^{\mathrm{d}}$, Osvaldo Pontiggiac, \\ Tayyaba Hasan ${ }^{\mathrm{e}}$, and Alcira Batlle ${ }^{\mathrm{a}}$ \\ a Centro de Investigaciones sobre Porfirinas y Porfirias (CIPYP). CONICET and Hospital de Clínicas José \\ de San Martín, University of Buenos Aires. Córdoba 2351 ler subsuelo; CP=1120AAF, Buenos Aires, \\ Argentina \\ b Instituto de Estudios Oncológicos, Academia Nacional de Medicina, Las Heras 3092, C1425ASU Buenos \\ Aires, Argentina
}

c Instituto Angel H Roffo. Av. San Martín 5481, Ciudad de Buenos Aires, Argentina

d Departamento de Biología, Facultad de Ciencias, Universidad Autónoma de Madrid. Cantoblanco E-28049 Madrid, Spain

e Wellman Laboratories of Photomedicine WEL-224, Department of Dermatology, Massachusetts General Hospital, Harvard Medical School, 55 Fruit Street, Boston, MA 02114, USA

\section{Abstract}

Photodynamic therapy (PDT) is a novel cancer treatment utilising a photosensitiser, visible light and oxygen. PDT often leaves a significant number of surviving tumour cells. In a previous work, we isolated and studied two PDT resistant clones derived from the mammary adenocarcinoma LM3 line (Int. J. Oncol. 29 (2006) 397-405). The isolated Clon 4 and Clon 8 exhibited a more fibroblastic, dendritic pattern and were larger than the parentals. In the present work we studied the metastatic potential of the two clones in comparison with LM3.

We found that $100 \%$ of LM3 invaded Matrigel, whereas only $19 \pm 6 \%$ and $24 \pm 7 \%$ of Clon 4 and Clon 8 cells invaded. In addition, $100 \%$ of LM3 cells migrated towards a chemotactic stimulus whereas $38 \pm 8 \%$ and $73 \pm 10 \%$ of Clones 4 and 8 respectively were able to migrate. In vivo, $100 \%$ of the LM3 injected mice developed spontaneous lung metastasis, whereas none of the Clon 8 did, and only one of the mice injected with Clon 4 did. No differences were found in the proteolytic enzyme profiles among the cells. Anchorage-dependent adhesion was also impaired in vivo in the resistant clones, evidenced by the lower tumour take, latency time and growth rates, although both clones showed in vitro higher binding to collagen I without overexpression of $\beta 1$ integrin.

This is the first work where the metastatic potential of cells surviving to PDT has been studied. PDT strongly affects the invasive phenotype of these cells, probably related to a higher binding to collagen. These findings may be crucial for the outcome of ALA-PDT of metastatic tumours, although further studies are needed to extrapolate the results to the clinic employing another photosensitisers and cell types.

Corresponding author Dr. Adriana Casas, Viamonte 188110 A, (1056) Ciudad de Buenos Aires, Argentina, FAX: 5411 4811 7447, Email: adriana@qb.fcen.uba.ar.

Publisher's Disclaimer: This is a PDF file of an unedited manuscript that has been accepted for publication. As a service to our customers we are providing this early version of the manuscript. The manuscript will undergo copyediting, typesetting, and review of the resulting proof before it is published in its final citable form. Please note that during the production process errors may be discovered which could affect the content, and all legal disclaimers that apply to the journal pertain. 


\section{Keywords}

photodynamic therapy; aminolevulinic acid; metastasis; invasion; adhesion

\section{INTRODUCTION}

Photodynamic therapy (PDT) is a novel cancer treatment modality utilising a photosensitiser, visible light and oxygen [1,2]. The photosensitiser absorbs light and, in the presence of oxygen, transfers the energy, producing cytotoxic oxygen species [3].

5-aminolevulinic acid (ALA) is an alternative compound for the treatment of malignant tumours $[4,5]$. ALA is a naturally occurring delta amino acid that is ultimately converted into Protoporphyrin IX (PpIX), the immediate precursor of heme and an endogenous photosensitiser.

Currently, topical photodynamic therapy (PDT) has received approval for the treatment of dermato-oncologic conditions like actinic keratoses, Bowen's disease, in-situ squamous cell carcinoma and basal cell carcinoma in many countries all over the world [6]. ALA is also frequently applied topically or systemically in PDT of superficial tumours such as cancer of the oral cavity, localised cutaneous lymphomas, and metastatic skin secondaries from breast or pinna [7] as well as non-tumour applications, especially psoriasis, viral-induced diseases, or acne vulgaris [8]. Non-superficial cancers such as duodenal, oesophageal, colorectal and cervical intraepithelial neoplasias, among others, have also been treated with ALA-PDT [9, $10,11]$. ALA has also been employed in the photodiagnosis and treatment of lung cancer, malignant glioma, bladder cancer and peritoneal carcinomatosis $[12,13,14,15]$.

The accumulation of ALA is more pronounced in malignant cells as compared to their normal counterparts in vitro and in vivo, and the reason for this phenomenon is attributed to an increase of the rate-limiting enzyme porphobilinogen deaminase [16,17], and a decrease of the acitivity of ferrochelatase in tumour cells [18].

PDT, similarly to the rest of the anticancer therapies, often leaves a significant number of surviving tumour cells which have been exposed to reactive oxygen species arising from light excitation of a photosensitiser, but not enough to be destroyed. The characteristics of the cells resistant to PDT allow us to study the changes induced in the long term by the treatment. These changes can be exploited to selectively treat the surviving cells either with modified PDT protocols or with other therapies [19].

A reduction of metastasis has been reported in vivo after PDT compared to surgery [20,21, 22]. Rousset et al [23] also reported a decrease of metastasis induced by colon adenocarcinoma cells treated with Photofrin-PDT respect to the control. On the contrary, Momma et al. [24], employing an orthopic prostate tumour model, showed that PDT induced an increase in the number of metastasis due to the induction of the vascular endothelial growth factor [25], which is reversed by simultaneous administration of antioangiogenic therapies [26].

Since the plasma membrane is the target for various photosensitisers [27], it is not surprising to find that PDT induces changes in cell adhesion, invasion and metastasis. In addition, tumour cells treated with PDT release prostanoids [28] that have been shown to influence the in vivo dissemination, and in vitro migration of carcinoma cells.

The metastasis process involves the detachment and infiltration of the cells from the original primary tumour. In the first step, the cells released from the primary tumour have to penetrate to the blood or lymphatic vessels. Circulating cells can then migrate through the walls of vessels 
to surrounding tissues (extravasation) where they settle, adhere, proliferate, and induce angiogenesis, creating metastasis. Circulating cells can then migrate through the walls of vessels to surrounding tissues (extravasation) where they settle, adhere, proliferate, and induce angiogenesis, creating metastasis. The processes of intra- and extravasation are regulated by the activation of proteolytic enzymes capable of degrading the extracellular matrix (ECM) [29].

In a previous work, we isolated and studied two ALA-PDT resistant clones from the murine mammary adenocarcinoma LM3 cell line [19]. The isolated clones exhibited a more fibroblastic, dendritic pattern, and a higher cell spreading while the parental line presented polyhedric shape, grew in clusters and was smaller. These different features led us to think that the resistant lines could present different adhesive, invasive or metastatic phenotypes.

In the present work we studied the metastatic potential of the clonal lines derived from the LM3 adenocarcinoma resistant to ALA-PDT. We examined in vitro the adhesion, migration and invasion processes, together with the proteolytic enzymes profile and in vivo, we assayed the ability of the resistant clones to induce spontaneous metastasis.

\section{MATERIALS AND METHODS}

\section{Chemicals}

Bovine serum albumin (BSA) was obtained from Sigma, St. Louis, MO, USA. Anti mouse monoclonal antibody against $\beta 1$-integrin was from Transduction Laboratories, UK and $\beta$-actin from GE Healthcare UK limited, Buckinghamshire, UK. The secondary antibody was peroxidase-conjugated goat anti-mouse IgG (Jackson ImmunoResearch Laboratories, Inc, West Grove, PA, USA). Fibronectin, laminin and Collagen I, were obtained from Collaborative Biomedical Products (Becton Dickinson, Bedford, MA, USA).

\section{Cell lines and cell cultures}

LM3 cell line [30] derived from the murine mammary adenocarcinoma M3 was cultured in minimum essential Eagle's medium supplemented with $2 \mathrm{mM}$ L-glutamine, $80 \mu \mathrm{g} / \mathrm{ml}$ gentamycin and $5 \%$ fetal bovine serum, and incubated at $37^{\circ} \mathrm{C}$ in an atmosphere containing $5 \% \mathrm{CO}_{2}$. Clon 4 and Clon 8 cells resistant to ALA-PDT were obtained after multiple ALAPDT treatments of LM3 parental cells as previously described [19].

\section{Animals}

Randomized inbred male BALB/c mice 12 weeks old, weighing 20-25 g were used. They were provided with food (Purina 3, Molinos Río de la Plata) and water ad libitum. Animals received human care and were treated in accordance with guidelines established by the Animal Care and Use Committee of the Argentine Association of Specialists in Laboratory Animals (AADEALC), in full accord with the UK Guidelines for the Welfare of animals in Experimental Neoplasia [31].

\section{Evaluation of tumour growth}

LM3 and the resistant clones were compared in their ability to growth as subcutaneous (s.c). primary tumours and to spontaneously metastasize to the lung. An amount of $10^{5}$ to $10^{6}$ cells/ $0.2 \mathrm{ml}$ were injected s.c. into the left flank of $\mathrm{BALB} / \mathrm{c}$ mice $(\mathrm{n}=7$ per point). Tumour volume was measured every week to establish the growth rate. Latency period was defined as the time when $50 \%$ of mice of each group developed palpable tumours. Tumour take was defined as the percentage of mice that developed palpable tumours at latency time. 


\section{Evaluation of spontaneous lung metastasis}

A cell suspension of $10^{6}$ cells $/ 0.2 \mathrm{ml}$ was injected s.c in the mice. When the tumours reached different fixed diameters, animals were sacrificed and the subpleural visible metastatic nodules were counted under a dissecting microscope. In addition, lungs were fixed in formaldehyde and embedded in paraffin according to standard histological procedures. Serial sections (4 um) from the whole lungs were cut and stained with $\mathrm{H} \& \mathrm{E}$ for counting metastasis in the parenchima.

\section{Invasion and chemotaxis assays}

The invasiveness of LM3 and resistant clones was tested in vitro in a 24-well insert system using an $8 \mu \mathrm{m}$ PET membrane coated with Matrigel Basement Membrane Matrix (BD BioCoat Matrigel invasion chambers, BD Biosciences, Bedford, MA, USA) following a described method [32]. Inserts were rehydrated with medium without serum according to manufacturer's instructions. Exponentially growing mammary tumour cells $\left(7 \times 10^{4}\right.$ cells/filter) suspended in medium without serum, were added to the upper chamber and assembled with the lower chamber, which had been prefilled with filtrated lung conditioned complete medium as chemoattractant [33]. After 20-hour incubation at $37^{\circ} \mathrm{C}$, the cells on the upper surface of the filter were removed with a cotton swab. Time and cell density conditions were established before. The filters were fixed with ice-cold methanol and stained with $0.1 \%$ crystal violet. The degree of invasion was measured by counting the number of cells in five randomly selected areas of the lower surface of the filter at $\times 400$ magnification. Tumour cell chemotaxis was measured following the same procedure employing the control inserts without the Matrigel coating.

Cell adhesion to ECM proteins: for adhesion assays, 96-well high binding plates were coated at $4{ }^{\circ} \mathrm{C}$ overnight with ECM proteins: $5 \mu \mathrm{g} \mathrm{ml}^{-1}$ fibronectin, $40 \mu \mathrm{g} \mathrm{ml}^{-1}$ laminin, and $20 \mu \mathrm{g}$ $\mathrm{ml}^{-1}$ collagen I dissolved in PBS $\mathrm{pH}$ 8.8. At least $1 \mathrm{~h}$ before the plates were used, the ECM liquid was discarded, and the wells were blocked with a solution of $0.5 \%$ bovine serum albumin (BSA). Cells $\left(5 \times 10^{5} \mathrm{ml}^{-1}\right)$ were trypsinised and plated in medium with BSA on the coated wells. Other wells were coated with BSA as a control for non-specific binding. After 30 min incubation at $37^{\circ} \mathrm{C}$, the cells were washed three times with PBS. The remaining adherent cells were fixed in methanol: acetone (1:1) for $15 \mathrm{~min}$. and stained with $0.5 \%$ crystal violet. Adherent cells were quantified by absorbance at $560 \mathrm{~nm}$ after solubilisation in $2 \%$ sodium dodecyl sulfate. Adhesion values were determined by quadruplicate measurements.

\section{Plating efficiency}

Cells were detached using trypsin/EDTA and resuspended in complete medium. Diluted suspensions were plated on $100 \mathrm{~mm}$ dishes and incubated for 10 days. Cells were fixed with ice-cold methanol and stained with $0.1 \%$ aqueous crystal violet. Colonies of more than 50 cells were counted.

\section{Detection of metalloprotease (MMP) activity}

Collagenolytic activity secreted by LM3 and ALA-PDT resistant cells was determined in conditioned media by gel electrophoresis SDS-polyacrylamide copolymerized with $0.1 \%$ gelatin. Protein content in the cells was determined with the Lowry et al. method [34] and the conditioned media were diluted before seeding. To detect specific activity, after running, the gels were washed in $2 \%$ Triton X-100 and incubated for $72 \mathrm{~h}$ in $0.25 \mathrm{M} \mathrm{Tris}-\mathrm{HCl} / 1 \mathrm{M} \mathrm{NaCl} /$ $25 \mathrm{mM} \mathrm{CaCl}_{2}$ buffer (pH 7.4). To detect non-specific activity, $40 \mathrm{mM}$ EDTA was added to the buffer solution. Gels were fixed and stained with Coomassie Blue. Gelatinolytic bands were identified by negative staining and quantified by a scan image densitometer coupled to an image analyzer. MMP activities were expressed as arbitrary units. 


\section{Immunoblots for $\beta 1$-integrin}

Semiconfluent monolayers were washed and then lysed with RIPA buffer [ $150 \mathrm{mM} \mathrm{NaCl}, 1 \%$ Triton X-100, $0.05 \%$ deoxycholate, $0.1 \%$ SDS, $1 \%$ Nonidet- $40,50 \mathrm{mM}$ Tris (pH 8)] containing Phosphatase cocktail 2 and Protease inhibitor cocktail (Sigma). The samples were adjusted to the same protein concentration (Bichinconinic acid protein assay kit, Pierce, Rockford, IL, USA), denatured by boiling in Laemmli sample buffer with 5\% $\beta$-mercaptoethanol and separated by SDS-PAGE, performed as described by Laemmli. Gels were electroblotted to a PDVF Immobilon-P membrane (Millipore, Bedford, MA, USA), blocked with 5\% skim milk in Tris buffered saline (Tris $\mathrm{HCl} 10 \mathrm{mM} \mathrm{pH} \mathrm{7.6,} \mathrm{NaCl} 0.9 \%, 0.05 \%$ Tween 20) overnight at $4^{\circ} \mathrm{C}$. Afterwards, the membranes were incubated $1 \mathrm{~h}$ at room temperature with a specific antibodiy anti $\beta 1$-integrin diluted 1:1000 in blocking buffer. Secondary antibody was used diluted 1:10,000 and incubated $1 \mathrm{~h}$ at room temperature. Detection was performed using ECL Plus Westernblotting detection system (GE Healthcare UK limited, Buckinghamshire, UK). Bands were quantified by scanning on a digital GS-700 densitometer and employing Molecular Analyst software.

\section{Statistical analysis}

Kruskal-Wallis test was employed to evaluate differences in the latency periods. The unpaired $t$-test was used to establish the significance of differences between groups in the rest of the experiments. Differences were considered statistically significant when $P<0.05$.

\section{RESULTS}

\section{Invasion in vitro}

Invasion was assayed in vitro (Figure 1) employing a 24-well insert system coated with Matrigel, using lung conditioned medium as chemoattractant. We observed that $100 \%$ of LM3 were able to invade Matrigel, whereas only $19 \pm 6 \%$ and $24 \pm 7 \%$ of Clon 4 and Clon 8 cells invaded.

In addition, we tested chemotaxis or directional migration using control inserts, and we saw that $100 \%$ of LM3 cells migrated through the porous membrane, whereas $38 \pm 8 \%$ and $73 \pm$ $10 \%$ of Clones 4 and 8 respectively were able to migrate.

\section{In vitro and in vivo behaviour}

Colony formation assay in vitro was significantly impaired (25-30\%) in both Clon 4 and Clon 8 compared to LM3 (Table 1).

Tumour take was decreased in the resistant clones compared with the LM3 line (Table 1), most markedly in Clon 8 . When $10^{5} \mathrm{LM} 3$ cells were injected s.c. into mice, $30 \%$ of mice developed tumours, whereas no tumours were developed in the resistant clones. Increasing the amount injected to $5 \times 10^{5}$ cells, tumour take was $100 \%$ for LM3 cells, $60 \%$ for Clon 4 and $30 \%$ for Clon 8. Further increasing the amount injected to $10^{6}$ cells, $100 \%$ of mice injected with LM3 and Clon 4 developed tumours, and only $60 \%$ of mice injected with Clon 8 did.

Growth rate was also significantly decreased in Clon $4(\mathrm{p}=0.047)$ compared with LM3, and Clon 8 growth delay was even more marked, 3.5 -fold lower than the control. Latency time was similar for LM3 and Clon 4 whereas it was markedly longer for Clon 8 cells ( $p<0.001)$.

\section{Induction of spontaneous metastasis}

Spontaneous lung metastasis induced by LM3 and resistant clones are shown in Figure 2. Whereas subcutaneous implanted LM3 cells mestastasised to lung in a tumour-size dependant 
way, Clones 8 and 4 almost did not induce nearly any metastasis at all. Only one small metastasis was found in one Clon 4 lung in the 7-19 $\mathrm{mm}$ tumour diameter range, whereas Clon 8 cells did not induce any metastasis at all.

\section{Cell adhesion}

We did not find any significant differences in the adhesion of the three cell lines to the ECM proteins fibronectin and laminin, whereas Clon 4 adhered 1.3-fold to Collagen I $(p=0.027)$ and Clon 8 adhered 2-fold (0.001) as compared to LM3 (Figure 3). BSA was employed as a non-ECM control.

\section{Metalloprotease activities}

Both LM3 and resistant clones exhibited strong MMP-9 and weak MMP-2 signals. However, the comparison of the arbitrary units obtained after quantification of both bands, revealed that there were no significant differences between LM3 and the resistant clones (Figure 4)

\section{Westernblot assays}

Westernblot assays did not show significant differences in the expression of $\beta 1$-integrin in the resistant clones as compared to LM3 cells (Figure 5).

\section{DISCUSSION}

In a previous work we had shown that the ALA-PDT resistant Clones 4 and 8 exhibited a more fibroblastic, dendritic pattern, and a higher spreading in plastic while the parental cell line presented polyhedric shape, grew in clusters and was smaller [19]. These different features led us to think that the resistant lines could present different adhesive, invasive or metastatic phenotypes.

In the present work we showed that the ALA-PDT resistant clones have a severely impaired metastatic potential. The metastasis process involves the detachment and infiltration of the cells from the original primary tumour, intravascular invasion, transport in the blood, extravasation, adhesion and ultimately, proliferation at the metastatic site [29]. We studied the differences in motility, invasion and adhesion of these low metastatic cell lines, and it is clear that some of these steps are altered.

Plating efficiency dropped significantly in Clon 4 and Clon 8 cells, and in vivo, tumour take and growth rate were also decreased in both clones, and latency time was longer in Clon 8 , showing that the general anchorage-dependent adhesion is somehow affected in these cells.

Proteolytic activity and remodelling of the extracellular matrix are important players in tumour progression. There is consensus to say that MMP activities correlate with higher metastatic potential [35]. However, during tumour regression the increase in cell death has been shown to be accompanied by an increase in proteolytic activity and extracellular matrix remodelling [34].

Both LM3 and resistant clones exhibit MMP-2 and MMP-9 activities, but no significant differences were found between LM3 and the resistant clones, suggesting that an impaired collagenolitic activity is not the reason for the different metastatic phenotype. It was found that PDT induced MMP-1 and MMP-3 activities in a fibroblast model [37], whereas PDT impaired MMP-2 and MMP-8 activities in glioma cells [38] and no alterations in the MMPs pattern were observed in some other PDT-treated cells [39,40]. 
Results from in vitro assays suggest that ALA-PDT resistant clones have a dramatic decrease in their ability to migrate and/or invade through Matrigel basement membranes. Whereas Clon 4 invading ability was 4-times lower than the LM3 parental cells, the migratory response was also impaired 2.5 times. Clon 8 presented the same decreased ability to invade as well, whereas the migratory response was only impaired 1.25 times. Since cell motility and chemotaxis are implicated in tumour-cell invasion [41], we believe that these are the main steps affecting the metastatic potential of LM3-derived cells. Moreover, since the migration process in Clon 8 was less markedly affected than the invasion, we hypothesise that the latter is the blocking point in the metastatic cascade in these cell types. Jiang et al. [42] also found that PDT with Photofrin reduced the invasiveness of malignat glioma spheroids through Matrigel-coated filters and normal fetal rat brain aggregates.

The adhesion process may either contribute to increase or to impair the metastatic potential of the cell, depending on the components involved in the adhesion process. It has been shown that loosening of cell-substrate interactions leads to increased invasion [43].

Collagen is found in significant amounts in basement membranes and it has been shown to promote attachment of both normal and neoplastic epithelial cells [44]. The highly metastatic subline of rat prostatic adenocarcinoma, MAT-LyLu was found to be less adherent to Collagen IV, compared to the low metastatic and high motile PIF-1 subline [45], and increased adhesion to collagen I has been correlated to decreased Matrigel invasion and metastasis [46,47]. On the other hand, higher adhesion to collagen IV increased the metastatic potential in other cell models $[48,49]$ and confers in vitro an increased motility and invasion [50,51].

In our ALA-PDT resistant model, there were no differences in the adhesion to laminin and fibronectin, but adhesion to collagen I was increased in both clones, more markedly in Clon 8 , and this process is likely to be restraining the ability to invade through Matrigel.

Some authors observed changes in the adhesion to plastic or endothelium in PDT-treated cells [52,53], transient impairment of some adhesion molecules expression [23,54], loss of focal adhesion plaques and alterations of integrin signalling [55,56]. In addition, several authors reported an increased resistance to trypsinisation after PDT, process mediated by cleavage of extracellular integrin fragments $[57,58,59,60]$.

Many studies have demonstrated that PDT alters the extracellular matrix profoundly, enhances the synthesis of collagen type I [61], increases platelet adhesion to collagen [62], and induces collagen cross-linkings [40]. In addition, PDT using Verteporfin transiently inhibits cell adhesion to collagen [55,56]. It is therefore, not surprising to find that ALA-PDT alters adhesion to collagen in ALA-PDT surviving cells.

Although we ignore which integrins are involved in the adhesion of LM3 cells to substrate, $\alpha 2 \beta 1$ integrin has been associated with breast cancer, and it was found to bind collagen I, laminin and tensacin [63]. However, we did not find overexpression of $\beta 1$ integrin in our resistant clones that could account for the increased adhesion to collagen I.

Since parental LM3 cells do not have a clonal origin, it is a heterogeneous population and we have to take into account that functional and morphologic changes present in the resistant clones, may be either arising after PDT treatments or just selected during the process of resistance. However, since cell membrane is one of the targets of ALA-PDT [64], inducing membrane cross-linkings, it is not surprising to find changes in adhesion, migration and invasion, driven by PDT treatment [65].

However, numerous cell components other than plasma membrane, including mitochondria, lysosomes, Golgi apparatus and nuclei have been described as targets for the cytotoxic effects 
of photodynamic therapy with other photosensitisers [66], and these different targets can lead to different metastatic phenotypes.

To sum up, this is the first work where the metastatic potential of cells resistant to PDT has been studied. We found that PDT strongly affects the invasive phenotype of these cells, probably related to a higher binding to collagen. These findings may be crucial for the clinical outcome of ALA-PDT of metastatic tumours. Further studies are needed to elucidate if this is a common feature of all the cells subjected to multiple PDT treatments, if any photosensitiser in any cell type would induce the same alterations and moreover, if these alterations would appear after in vivo photodynamic treatment.

\section{Acknowledgements}

This research was funded by grants from the National Cancer Center PO1 CA84203, the National Institutes for Health RO1 AR040352, the Department of Defense FA 9550-04-1-0079, and the Argentine National Research Council (CONICET) (PIP 4108/96, 5263/05 and 105508/99-00). During the writing of this article, support to the authors was provided by National Institute of Health Grants PO1 CA084203 and RO1 AR040352. A.C. thanks Bunge y Born Foundation and Jorge Oster Argentina for financial support.

\section{Abbreviations}

ALA

5-aminolevulinic acid

ALA-PDT

ALA-based PDT

BSA

bovine serum albumin

ECM

extracellular matrix

MMP

matrix metalloprotease

PBS

phosphate-buffered saline

PDT

photodynamic therapy

s.c

subcutaneous

\section{References}

1. Dougherty T. Photodynamic therapy (PDT) of malignant tumours. Crit Rev Oncol Hematol 1984;2:83116. [PubMed: 6397270]

2. Gomer, C. Photodynamic Therapy. Pergamon Press; Oxford, England: 1987.

3. Weishaupt K, Gomer C, Dougherty T. Identification of singlet oxygen as the cytotoxic agent in photoactivation of a murine tumour. Cancer Res 1976;36:2326-2329. [PubMed: 1277137]

4. Kennedy J, Pottier R, Pross G. Photodynamic Therapy with endogenous protoporphyrin IX: basic principles and present clinical experience. J Photochem Photobiol B 1990;6:143-148. [PubMed: 2121931] 
5. Fukuda H, Casas A, Chueke F, Paredes S, Batlle A. Photodynamic action of endogenously syntesized porphyrins from aminolevulinic acid, using a new model for assaying the effectiveness of tumoural cell killing. Int J Biochem 1993;25:1395-1398. [PubMed: 8224354]

6. Babilas P, Landthaler M, Szeimies R. Photodynamic therapy in dermatology. Eur J Dermatol 2006;16:340-8. [PubMed: 16935788]

7. Cairnduff F, Stringer MR, Hudson EJ, Ash DV, Brown SB. Superficial photodynamic therapy with topical 5-aminolaevulinic acid for superficial primary and secondary skin cancer. Br J Cancer 1994;69:605-608. [PubMed: 8123497]

8. Fritsch C, Ruzicka T. Fluorescence diagnosis and photodynamic therapy in dermatology from experimental state to clinic standard methods. J Environ Pathol Toxicol Oncol 2006;25:425-439. [PubMed: 16566733]

9. Kelty CJ, Brown NJ, Reed MW, Ackroyd R. The use of 5-aminolaevulinic acid as a photosensitiser in photodynamic therapy and photodiagnosis. Photochem Photobiol Sci 2002;1:158-168. [PubMed: 12659511]

10. Kurwa H, Barlow R. The role of photodynamic therapy in dermatology. Clin Exp Der 1999;24:143148.

11. Gossner L, Stolte M, Sroka R, Rick K, May A, Hahn E, Ell C. Photodynamic ablation of high-grade dysplasia and early cancer in Barrett's esophagus by means of 5-aminolevulinic acid. Gastroenterology 1998;114:448-455. [PubMed: 9496934]

12. Hautmann H, Pichler JP, Stepp H, Baumgartner R, Gamarra F, Huber RM. In-vivo kinetics of inhaled 5-aminolevulinic acid-induced protoporphyrin IX fluorescence in bronchial tissue. Respir Res 2007;8:33. [PubMed: 17445266]

13. Stepp H, Beck T, Pongratz T, Meinel T, Kreth FW, Tonn JCh, Stummer W. ALA and malignant glioma: fluorescence-guided resection and photodynamic treatment. J Environ Pathol Toxicol Oncol 2007;26:157-164. [PubMed: 17725542]

14. Kriegmair M, Baumgartner R, Knuechel R, Stepp H, Hofstadter F, Hofstetter A. Detection of early bladder cancer by 5-aminolevulinic acid induced porphyrin fluorescence. J Urology 1996;155:105110.

15. Gahlen J, Prosst RL, Pietschmann M, Haase T, Rheinwald M, Skopp G, Stern J, Herfarth C. Laparoscopic fluorescence diagnosis for intraabdominal fluorescence targeting of peritoneal carcinosis experimental studies. Ann Surg 2002;60:235-252.

16. Navone N, Polo C, Frisardi A, Andrade N, Batlle A. Heme biosynthesis in human breast adenocarcinoma. Mimetic in vitro studies and some heme enzymic activity levels. Int J Biochem 1990;22:1407-1411. [PubMed: 2276414]

17. Navone N, Polo C, Frisardi A, Batlle A. Mouse mammary carcinoma PBGase and hydroxymethylbilane synthetase. Comp Biochem Physiol B 1991;98:67-71. [PubMed: 2060282]

18. Van Hillesberg R, Van der Berg J, Kort W, Terpstra O, Wilson J. Selective accumulation of endogenously produced porphyrins in a liver metastasis model in rats. Gastroenterology 1992;103:647-651. [PubMed: 1386052]

19. Casas A, Perotti C, Ortel B, Di Venosa G, Saccoliti M, Batlle A, Hasan T. Induction of murine tumour cell lines ressistant to ALA-mediated Photodynamic Therapy. Int J Oncol 2006;29:397-405. [PubMed: 16820882]

20. Gomer C, Ferrario A, Murphree A. The effect of localized porphyrin photodynamic therapy on the induction of tumour metastasis. Br J Cancer 1987;56:27-32. [PubMed: 2956984]

20. Schreiber S, Gross S, Brandis A, Harmelin A, Rosenbach A, Belkin V, Scherz A, Salomon Y. Local photodynamic therapy (PDT) of rat C6 glioma xenografts with Pd-bacteriopheophorbide leads to decreased metastases and increase of animal cure compared with surgery. Int J Cancer 2002;99:279285. [PubMed: 11979445]

22. Lisnjak I, Kutsenok V, Polyschuk L, Gorobets O, Gamaleia N. Effect of photodynamic therapy on tumour angiogenesis and metastasis in mice bearing Lewis lung carcinoma. Exp Oncol 2005;27:333335. [PubMed: 16404357]

23. Rousset N, Vonarx V, Eleouet S, Carre J, Kerninon E, Lajat Y, Patrice T. Effects of photodynamic therapy on adhesion molecules and metastasis. J Photochem Photobiol B 1999;52:65-73. [PubMed: 10643074] 
24. Momma T, Hamblin M, Wu H, Hasan T. Photodynamic therapy of orthotopic prostate cancer with benzoderivative: local control and distant metastasis. Cancer Res 1998;58:5425-5431. [PubMed: 9850075]

25. Solban N, Selbo P, Sinha A, Chang S, Hasan T. Mechanistic investigation and implications of photodynamic therapy induction of vascular endothelial growth factor in prostate cancer. Cancer Res 2006;66:5633-40. [PubMed: 16740700]

26. Kosharskyy B, Solban N, Chang S, Rizvi I, Chang Y, Hasan T. A mechanism-based combination therapy reduces local tumour growth and metastasis in an orthotopic model of prostate cancer. Cancer Res 2006;66:10953-10958. [PubMed: 17108133]

27. Moor AC. Signaling pathways in cell death and survival after photodynamic therapy. J Photochem Photobiol B 2000;57:1-13. [PubMed: 11100832]

28. Cecic I, Korbelik M. Mediators of peripheral blood neutrophilia induced by photodynamic therapy of solid tumors. Cancer Lett 2002;183:43-51. [PubMed: 12049813]

29. Christofori G. New signals from the invasive front. Nature 2006;441:444-50. [PubMed: 16724056]

30. Werbajh S, Urtreger A, Puricelli L, De Lustig E, Bal de Kier Joffe E, Kornblihtt A. Downregulation of fibronectin transcription in highly metastatic adenocarcinoma cells. FEBS Lett 1992;440:277281. [PubMed: 9872386]

31. Workman P, Balmain A, Hickman J. United Kingdom Co-ordinating Comittee on Cancer Research (UKCCCR) guidelines for the welfare of animals in experimental neoplasia (Second Edition). Br J Cancer 1998;77:1-10.

32. Albini A, Iwamoto Y, Kleinman H, Martin G, Aaronson S, Kozlowski J, McEwan RN. A rapid in vitro assay for quantitating the invasive potential of tumour cells. Cancer Res 1987;47:3239-3245. [PubMed: 2438036]

33. Ladeda V, Adam A, Puricelli L, Bal de Kier Joffe E. Apoptotic cell dearth in mammary adenocarcinoma cells is prevented by soluble factors present in the target organ of metastasis. Breast Cancer Res Treat 2001;69:39-51. [PubMed: 11759827]

34. Lowry O, Rosebrough N, Farr L, Randall R. Protein measurement with the folin phenol reagents. J Biol Chem 1951;193:265-275. [PubMed: 14907713]

35. Liotta L, Steeg P, Stetler-Stevenson W. Cancer metastasis and angiogenesis: an inbalance of positive and negative regulation. Cell 1991;64:327-336. [PubMed: 1703045]

36. Simian M, Molinolo A, Lanari C. Involvement of matrix metalloproteinase activity in hormoneinduced mammary tumor regression. Am J Pathol 2006;168:270-279. [PubMed: 16400029]

37. Karrer S, Bosserhof A, Weiderer P, Landthaler M, Szeimies R. Influence of 5-aminolevulinic acid and red light on collagen metabolism of human dermal fibroblasts. J Invest Dermatol 2003;120:325331. [PubMed: 12542540]

38. Au C, Luk S, Jackson C, Ng H, Yow C, To S. Differential effects of photofrin, 5-aminolevulinic acid and calphostin C on glioma cells. J Photochem Photobiol B 2006;85:92-101. [PubMed: 16829117]

39. Overhaus M, Heckenkamp J, Kossodo S, Leszcynski D, LaMuraglia G. Photodynamic Therapy generates a matrix barrier to invasive vascular cell migration. Circ Res 2000;86:334-340. [PubMed: 10679486]

40. Waterman PR, Overhaus M, Heckenkamp J, Nigri GR, Fungaloi PF, Landis ME, Kossodo SC, LaMuraglia GM. Mechanisms of reduced human vascular cell migration after photodynamic therapy. Photochem Photobiol 2002;75:46-50. [PubMed: 11841040]

41. Eccles S. Targeting key steps in metastatic tumour progression. Curr Opin Genet Dev 2005;15:7786. [PubMed: 15661537]

42. Jiang F, Chopp M, Katakowski M, Cho KK, Yang X, Hochbaum N, Tong L, Mikkelsen T. Photodynamic therapy with Photofrin reduces invasiveness of malignant human glioma cells. Lasers Med Sci 2002;17:280-288. [PubMed: 12417983]

43. Pauli B, Schwartz D, Thonar E, Kuettner K. Tumour invasion and host extracellular matrix. Cancer Metastasis Rev 1983;2:129-152. [PubMed: 6352011]

44. Terranova V, Rohrbach D, Martin G. Role of laminin in the attachment of PAM 212 (epithelial) cells to basement membrane collagen. Cell 1980;22:719-726. [PubMed: 7460011] 
45. Mohler JL, Levy F, Sharief Y. Metastatic potential and substrate dependence of cell motility and attachment in the Dunning R-3327 rat prostatic adenocarcinoma model. Cancer Res 1991;51:65806585. [PubMed: 1742730]

46. Yoshimura M, Nishikawa A, Ihara Y, Taniguchi S, Taniguchi NN. Suppression of lung metastasis of B16 mouse melanoma by N-acetylglucosaminyltransferase III gene transfection. Proc Natl Acad Sci USA 1995;92:8754-8758. [PubMed: 7568011]

47. Ek E, Dass C, Contreras K, Choong P. Inhibition of orthotopic osteosarcoma growth and metastasis by multitargeted antitumour activities of pigment epithelium-derived factor. Clin Exp Metastasis 2007;24:93-106. [PubMed: 17458711]

48. Dumont J, Jones W, Bitonti A. Inhibition of experimental metastasis and cell adhesion of B16F1 melanoma cells by inhibitors of protein kinase C. Cancer Res 1992;52:1195-1200. [PubMed: 1737379]

49. Lichtner R, Kaufmann A, Kittmann A, Rohdeschulz B, Walter J, Williams L, Ullrich A, Schirrmacher $\mathrm{V}$, Khazaie K. Ligand mediated activation of ectopic EGF receptor promotes matrix protein adhesion and lung colonization of rat mammary adenocarcinoma cells. Oncogene 1995;10:1823-1832. [PubMed: 7753557]

50. Azzam H, Thompson E. Collagen-induced activation of the $M_{\mathrm{r}} 72,000$ type IV collagenase in normal and malignant human fibroblastoid cells. Cancer Res 1992;52:4540-4544. [PubMed: 1322793]

51. Savarese D, Russel J, Fatatis A, Liotta L. Type IV collagen stimulates an increase in intracellular calcium: potential in tumour cell motility. J Biol Chem 1992;267:21928-21935. [PubMed: 1328249]

52. Foultier M, Vonarx V, Cordel S, Combre A, Patrice T. Modulation of colonic cancer cell adhesiveness by hematoporphyrin derivative photodynamic therapy. J Photochem Photobiol B: Biol 1994;23:917.

53. Vonarx V, Moultier M, de Brito X, Anasagasti L, Morlet L, Patrice T. Photodynamic therapy decreases cancer colonic cell adhesiveness and metastatic potential. Res Exp Med 1995;195:101-116.

54. Uzdensky A, Juzeniene A, Kolpakova E, Hjortland G, Juzenas P, Moan J. Photosensitization with protoporphyrin IX inhibits attachment of cancer cells to a substratum. Biochem Biophys Res Commun 2004;322:452-457. [PubMed: 15325251]

55. Runnels J, Chen N, Ortel B, Kato D, Hasan T. BPD-MA-mediated photosensitization in vitro and in vivo: cellular adhesion and $\beta_{1}$ integrin expression in ovarian cancer cells. Br J Cancer 1999;80:946953. [PubMed: 10362101]

56. Margaron P, Sorrenti L, Levi J. Photodynamic therapy inhibits cell adhesion without altering integrin expression. Biochim Biophys Acta 1997;359:200-210. [PubMed: 9434126]

57. Denstman S, Dillehay L, Williams J. Enhanced susceptibility to HpD-sensitized phototoxicity and correlated resistance to trypsin detachment in SV40 transformed IMR-90 cells. Photochem Photobiol 1986;43:145-147. [PubMed: 3010344]

58. Ball D, Mayhew S, Vernon D, Griffin M, Brown S. Decreased efficiency of trypsinization of cells following photodynamic therapy: evaluation of a role for tissue transglutaminase. Photochem Photobiol 2001;73:47-53. [PubMed: 11202365]

59. Uzdensky A, Juzeniene A, Ma L, Moan J. Photodynamic inhibition of enzymatic detachment of human cancer cells from a substratum. Biochim Biophys Acta 2004;1670:1-11. [PubMed: 14729136]

60. Tsai J, Wu C, Chien H, Chen C. Reorganization of cytoskeleton induced by 5-aminolevulinic acidmediated photodynamic therapy and its correlation with mitochondrial dysfunction. Lasers Surg Med 2005;36:398-408. [PubMed: 15856508]

61. Uehara M, Inokuchi T, Tobita T, Ohba S, Asahina I. Expression of heat shock protein 47 in the fibrous tissue adjacent to mouse tumour subjected to photodynamic therapy. Oral Oncol 2007;43:804-810. [PubMed: 17174144]

62. Fungaloi P, Statius van Eps R, Wu YP, Blankensteijn J, de Groot P, van Urk H, van Hillegersberg R, LaMuraglia G. Platelet adhesion to photodynamic therapy-treated extracellular matrix proteins. Photochem Photobiol 2002;75:412-417. [PubMed: 12003132]

63. Uhm J, Gladson C, Rao J. The role of integrins in the malignant phenotype of gliomas. Frontiers Biosci 1999;4:d188-199.

64. Girotti A. Photosensitized oxidation of membrane lipids: reaction pathways, cytotoxic effects, and cytoprotective mechanisms. J Photochem Photobiol B 2001;63:103-113. [PubMed: 11684457] 
65. Shen H, Spikes J, Kopecekov A, Kopecek J. Photodynamic crosslinking of proteins. I. Model studies using histidine- and lysine-containing N-(2-hydroxypropyl)methacrylamide copolymers. J Photochem Photobiol B 1996;34:203-210. [PubMed: 8810538]

66. Stockert JC, Juarranz A, Villanueva A, Nonell S, Horobin R, Soltermann A, Durantini E, Rivalona V, Colombo L, Espada JM, Cañete M. Photodynamic therapy:selective uptake of photosensitizing drugs into tumor cells. Curr Topics Pharmacol 2004;8:185-217. 


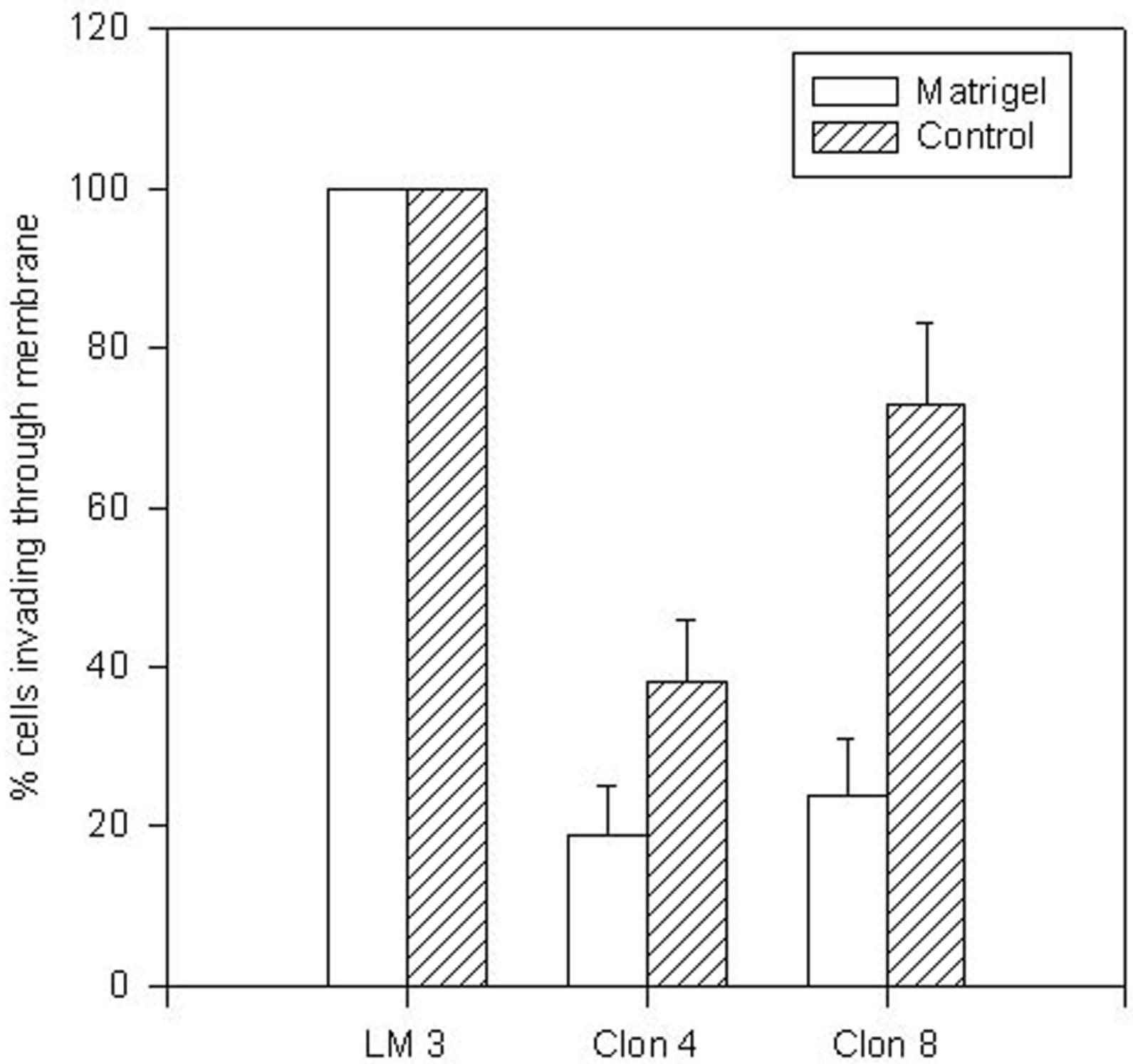

Figure 1. In vitro migration and invasion of LM3, Clon 4 and Clon 8

The invasiveness of the cells was tested in vitro in Matrigel-coated inserts, whereas the chemotaxis was measured using the control uncoated inserts. Bars, means \pm SD of 4 independent experiments run in triplicate. The results are expressed as \% of total cells plated in the inserts. 


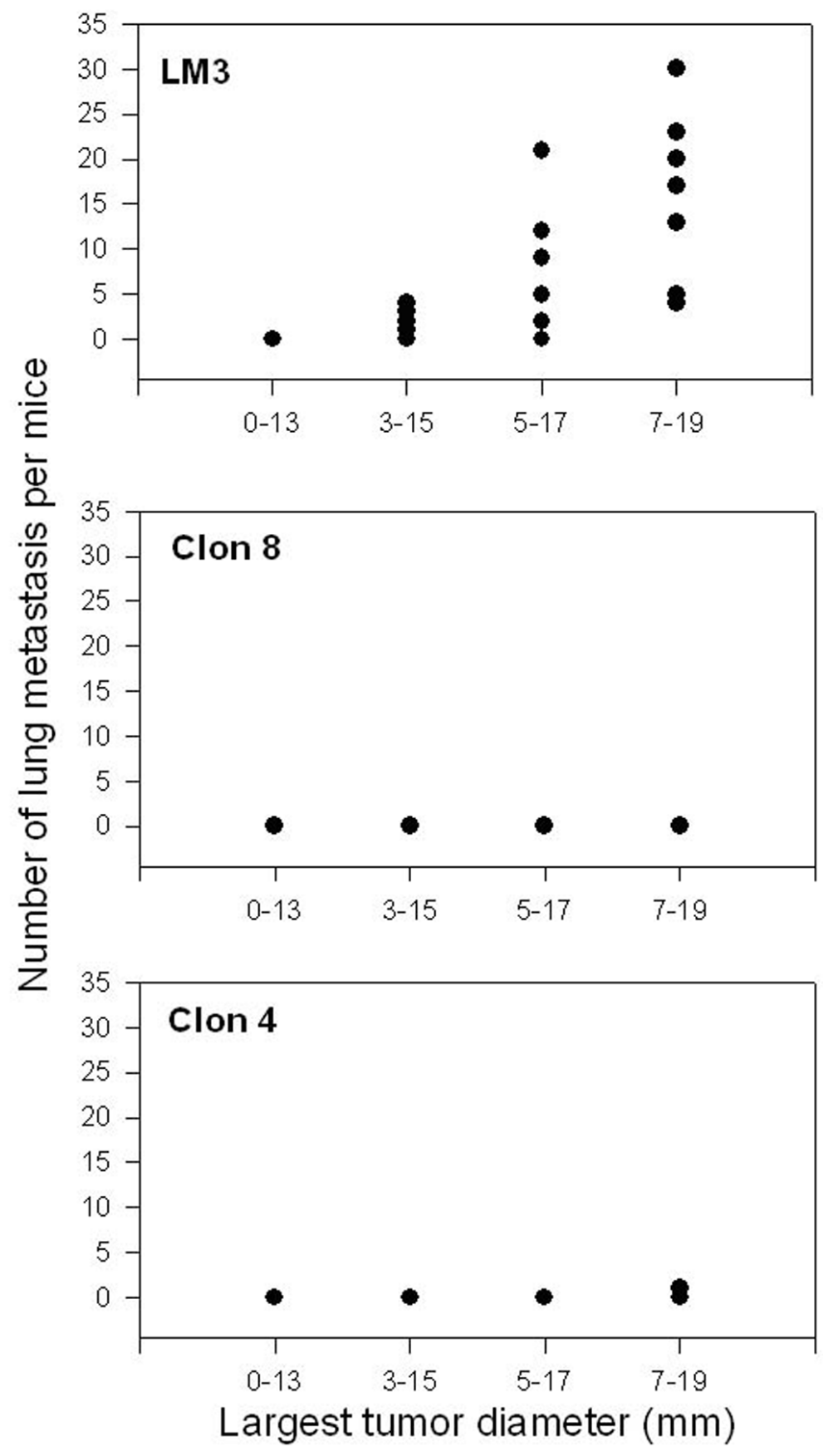

Figure 2. Lung spontaneous metastasis induced by LM3, Clon 4 and Clon 8 A cell suspension of $10^{6}$ cells $/ 0.2 \mathrm{ml}$ was injected s.c. When the tumour reached different fixed diameters, animals were sacrificed and the total number of metastasis (macroscopic + microscopic) were counted. Points, number of metastasis of single mouse. At least 7 mice per point were used. 


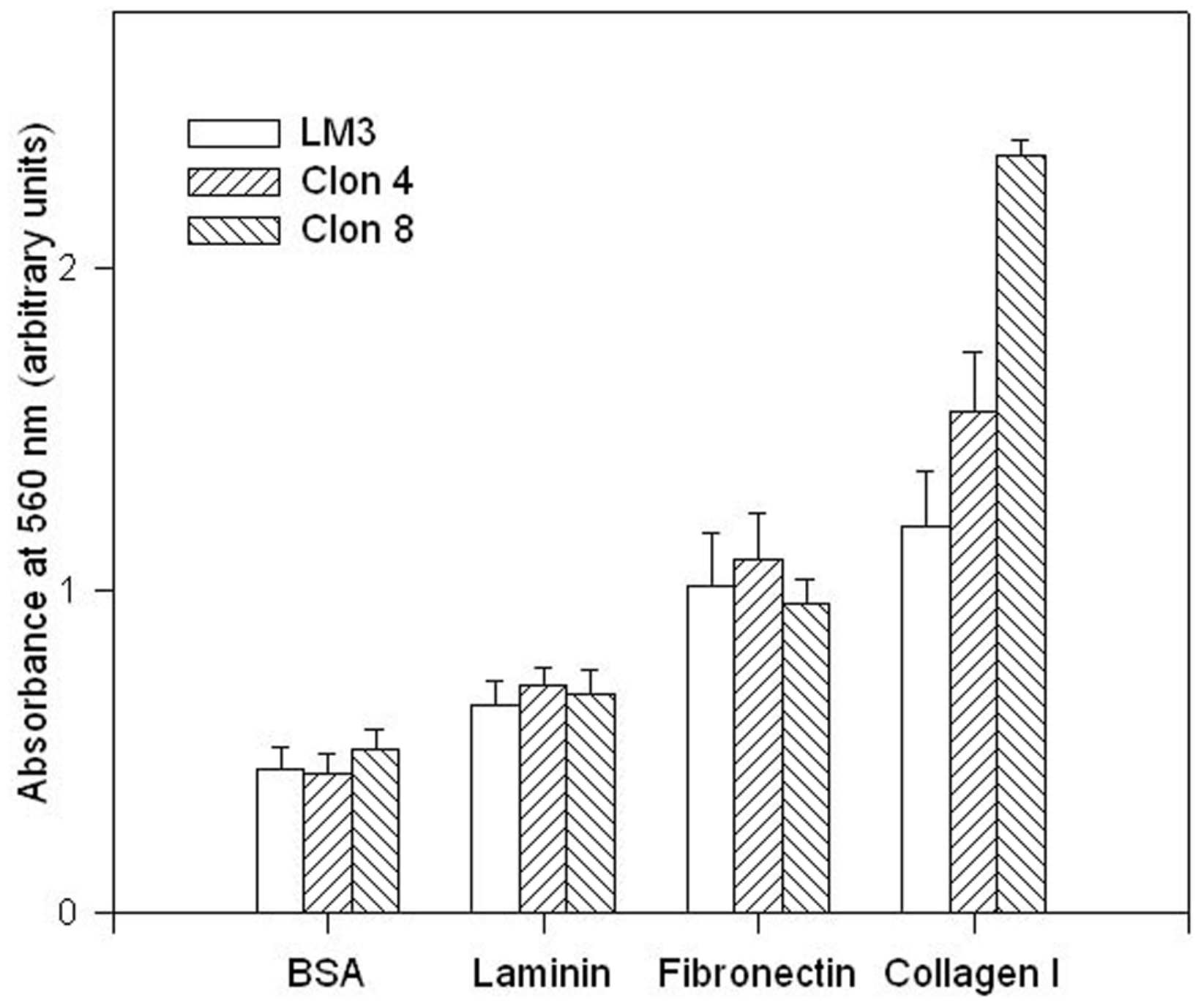

Figure 3. Cell adhesion of LM3, Clon 4 and Clon 8 cells to ECM proteins

After 30 min of culture on BSA, laminin, fibronectin or collagen I, cells were quantified using a colorimetric method described in Materials and Methods. The Figure illustrates results from one representative experiment of 3 ; each experimental condition is mean \pm SE from 4 individual samples. 


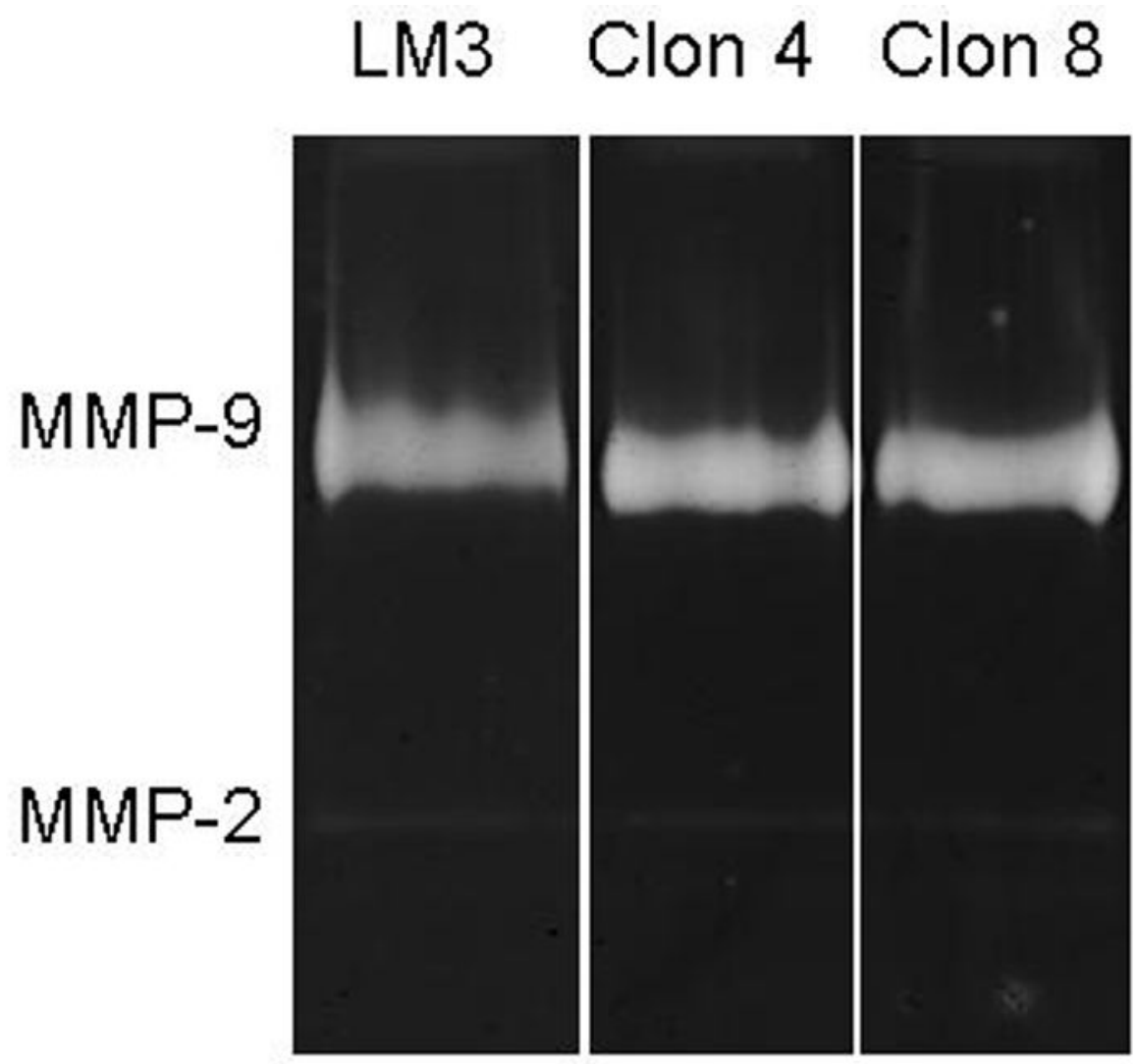

Figure 4. Gelatin zymography of conditioned culture media of LM3, Clon 4 and Clon 8 cells A representative image of a gelatin zymogram is shown. 


\title{
LM3 Clon 4 Clon 8
}

\section{$\beta 1$-integrin}

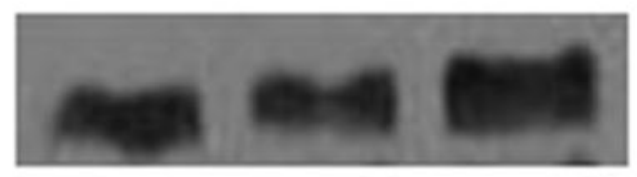

\author{
Actin
}

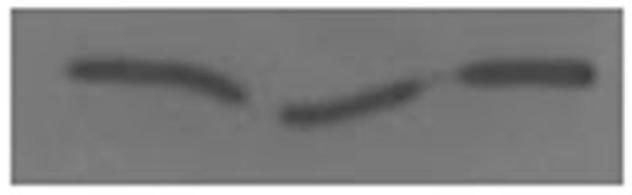

Figure 5. Western blot analysis $\beta 1$-integrin

Total extracts of subconfluent cultures were employed. Actin was employed as a loading control. The figure is representative of at least three independent experiments 
Table 1

In vitro and in vivo behaviour of LM3 and resistant clones injected subcutaneously in mice

\begin{tabular}{llll}
\hline & LM3 & Clone 4 & Clone 8 \\
\hline Plating efficiency $(\%)^{a}$ & $95 \pm 8$ & $75 \pm 10^{*}$ & $70 \pm 4$ \\
Tumour take $(\%)\left(10^{6} / 5 \times 10^{5} / 10^{5}\right.$ cells/mouse) $b$ & $100 / 100 / 30$ & $100 / 60 / 0$ & $60 / 30 / 0$ \\
${\text { Growth rate in exponential phase }\left(\mathrm{cm}^{3} / \text { day) }\right.}^{\mathrm{c}}$ & $0.091 \pm 0.017$ & $0.075 \pm 0.015^{*}$ & $0.025 \pm 0.001^{*}$ \\
Latency (days) $^{d}$ & $20(15-23)$ & $22(17-27)$ & $35(28-45)$ \\
& & & \\
\hline
\end{tabular}

$a_{n=3}$

$b_{n=5}$ per point.

$c, d{ }_{10}^{6}$ cells/mouse, $n=9$, three independent experiments.

$d$

mean (range).

p $<0.05$ vs. LM3, unpaired Student's $t$-test.

**

$\mathrm{p}<0.001$ vs. LM3, Kruskal-Wallis test. 